\title{
Spontaneous Pneumomediastinum/Pneumothorax in Patients With COVID-19
}

\author{
Bianka Eperjesiova ${ }^{1}$, Eric Hart ${ }^{1}$, Mohamed Shokr $^{2}$, Prabhat Sinha ${ }^{1}$, Gary T. Ferguson ${ }^{3}$ \\ 1. Pulmonary and Critical Care Medicine, Ascension Providence Hospital, Southfield, USA 2. Cardiology, Detroit \\ Medical Center, Detroit, USA 3. Pulmonary and Critical Care Medicine, Pulmonary Research Institute of Southeastern \\ Michigan, Farmington Hills, USA
}

Corresponding author: Bianka Eperjesiova, eperjesiova.bianka@gmail.com

\begin{abstract}
No spontaneous air leak case series have been described in the severe acute respiratory syndrome coronavirus 2 (SARS-CoV-2) patient population thus far. We described seven spontaneous air leak cases we found in our coronavirus disease 2019 (COVID-19) positive 976-patient cohort. Five out of seven patients eventually required mechanical ventilation, and one of these patients died. All of our patients who demonstrated radiological air leaks after intubation died. No other precipitating factors offered in the literature thus far played a role in our patient population. We presume that acute lung injury leading to SARS-CoV-2 with associated acute respiratory distress syndrome (ARDS) predisposes patients to this rare complication.
\end{abstract}

Categories: Internal Medicine, Infectious Disease, Pulmonology

Keywords: pneumothorax, pneumomediastinum, covid-19, mechanical ventilation

\section{Introduction}

Spontaneous air leak is the travel of free air following distended ruptured alveoli via peribronchovascular sheaths into the mediastinum or the pleural space [1]. It can occur in the setting of obstructive or restrictive lung disease exacerbation, although it has been observed in hyperventilation states such as infections, vomiting, diabetic ketoacidosis, athletic activities, or inhalational drug abuse [2]. Air leak in hospitalized severe acute respiratory syndrome coronavirus 2 (SARS-CoV-2) patients has been sparsely published as case reports, however, the presence of non-invasive ventilation and positive airway pressure were reported prior to this finding [3-4]. Additionally, there is no reported incidence found in the literature. Studies of a severe acute respiratory syndrome with SARS did identify air leak as a frequent complication, often with no relation to intubation or positive pressure ventilation [1-5].

Received 06/19/2020 Review began 06/25/2020 Review ended 06/28/2020 Published 07/03/2020

() Copyright 2020

Eperjesiova et al. This is an open access article distributed under the terms of the Creative Commons Attribution License CC-BY 4.0., which permits unrestricted use, distribution, and reproduction in any medium, provided the original author and source are credited.

\section{Case Presentation}

Our institution cared for 976 coronavirus disease 2019 or COVID-19 (SARS-CoV-2) patients between March 8 and April 15, 2020. Of these, we found 20 cases of air leak; three traumatic/post-procedure, 10 postintubation/mechanical ventilation, and seven spontaneous (five cases of pneumomediastinum and two isolated pneumothorax). The demographic, clinical, laboratory, and imaging data of the seven patients who developed a spontaneous air leak are provided in Table 1. 


\section{Cureus}

\begin{tabular}{|c|c|c|c|c|c|c|c|}
\hline & Patient 1 & Patient 2 & Patient 3 & Patient 4 & Patient 5 & Patient 6 & Patient 7 \\
\hline $\begin{array}{l}\text { IIming in relation to } \\
\text { invasive ventilation }\end{array}$ & Never Intubated & Before & Betore & $\begin{array}{l}\text { Never } \\
\text { Intubated }\end{array}$ & Before & Before & Before \\
\hline $\begin{array}{l}\text { Pneumomediastinum } \\
\text { (PM)/Subcutaneous } \\
\text { emphysema } \\
\text { (SE)/Pneumothorax (PTX) }\end{array}$ & $\begin{array}{l}\text { PM, SE extending } \\
\text { into the neck }\end{array}$ & PM, SE & $\mathrm{PM}, \mathrm{SE}$ & PTX & $\mathrm{PM}, \mathrm{SE}$ & Right PIX & Right PTX \\
\hline $\begin{array}{l}\text { Days from Admission to } \\
\text { Event }\end{array}$ & 0 & 10 & 15 & 0 & 0 & 18 & 0 \\
\hline Cough & No known cough & Mild cough & Forceful & Forceful & Forceful & Forceful & Forceful \\
\hline $\begin{array}{l}\text { Maximum Respiratory } \\
\text { Rate }\end{array}$ & 24 & 18 & 30 & 20 & 17 & 28 & 32 \\
\hline Smoking Status & Active & Never & Never & Never & Never & Never & Never \\
\hline $\begin{array}{l}\text { History of Pulmonary } \\
\text { Disease }\end{array}$ & Emphysema & None & Asthma & None & Asthma & None & None \\
\hline Lactate mmol/L (Initial) & 4.3 & 1.8 & 2.6 & N/A & 3.3 & 2.4 & 3.4 \\
\hline $\begin{array}{l}\text { Other Computed } \\
\text { Tomography Findings }\end{array}$ & $\begin{array}{l}\text { Diffuse Airspace } \\
\text { Disease with } \\
\text { Ground Glass } \\
\text { Opacities (GGOs) }\end{array}$ & $\begin{array}{l}\text { Diffuse } \\
\text { Airspace } \\
\text { Disease } \\
\text { with GGOs }\end{array}$ & $\begin{array}{l}\text { Diffuse } \\
\text { Airspace } \\
\text { Disease } \\
\text { with GGOs }\end{array}$ & $\begin{array}{l}\text { Diffuse } \\
\text { Airspace } \\
\text { Disease } \\
\text { with GGOs }\end{array}$ & $\begin{array}{l}\text { Diffuse } \\
\text { Airspace } \\
\text { Disease } \\
\text { with GGOs }\end{array}$ & $\begin{array}{l}\text { Diffuse } \\
\text { Airspace } \\
\text { Disease } \\
\text { with GGOs }\end{array}$ & $\begin{array}{l}\text { Diffuse Airspace Disease } \\
\text { with GGOs and Right } \\
\text { Lower Lobe (RLL) } \\
\text { Consolidation }\end{array}$ \\
\hline Chest Tube Placement & No & No & No & Yes & No & Yes & Yes \\
\hline $\begin{array}{l}\text { Air Leak Radiological } \\
\text { Resolution }\end{array}$ & Yes & No & Yes & Yes & No & Yes & Yes \\
\hline Length of stay (days) & 14 & 15 & 25 & 22 & 40 & 36 & 15 \\
\hline
\end{tabular}

TABLE 1: Demographic, laboratory, and radiological data for seven COVID-19 patients with spontaneous air leak

A typical clinical scenario is described as follows. A 54-year-old woman, with a history of hypertension presented with altered mental status. She was hemodynamically stable but with mild hypoxemia. She was COVID-19 positive, had elevated inflammatory markers, and acute renal failure requiring dialysis. Computed tomography (CT) scan showed changes consistent with acute respiratory distress syndrome (ARDS) plus pneumomediastinum with subcutaneous emphysema extending into the neck (Figure 1 - 1A). The patient was treated medically, and no mechanical ventilation was required. Her hospital course was complicated by a bleeding duodenal ulcer, ischemic stroke, and fungemia. Fourteen days later, CT showed a resolution of pneumomediastinum (Figure 1 - 1B). She was discharged to subacute care. Similarly for patient 5, CT was performed (Figure $1-5 \mathrm{~A}, 5 \mathrm{~B}$ ). 


\section{Cureus}
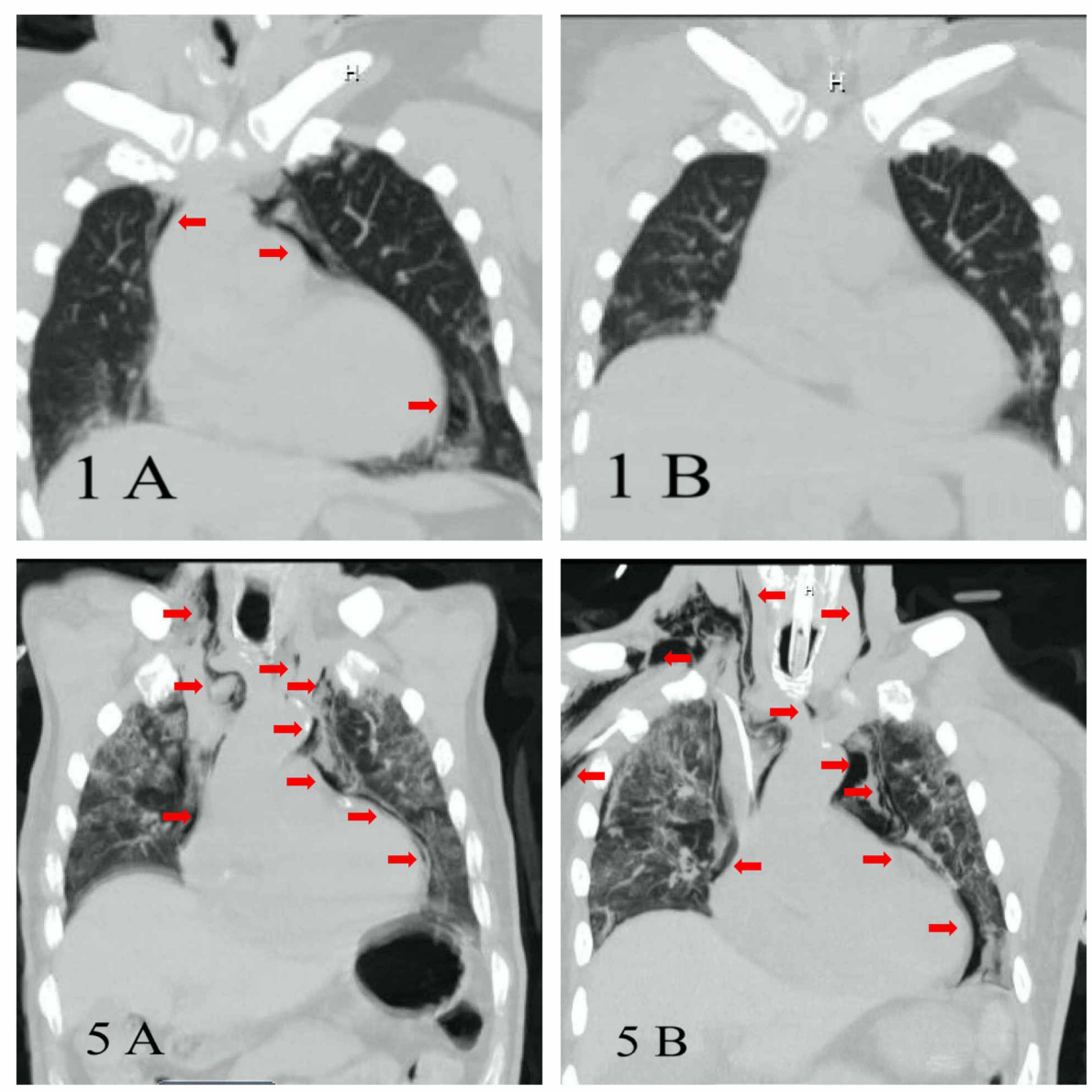

\section{FIGURE 1: Computed tomography (CT) of the chest for patient 1 and patient 5 showing initial and follow-up imaging}

$1 \mathrm{~A}$ - CT chest with pneumomediastinum extending into the subcutaneous emphysema in the neck and bilateral ground glass opacifications, 1B - CT chest showing resolution of the air leak, $5 \mathrm{~A}-\mathrm{CT}$ chest with pneumomediastinum tracking into the neck, $5 \mathrm{~B}$ - CT chest post-intubation with severe worsening of the air leak

The patient was treated medically, and no mechanical ventilation was required. Her hospital course was complicated by a bleeding duodenal ulcer, ischemic stroke, and fungemia. Fourteen days later, CT showed the resolution of pneumomediastinum (Figure 1 - 1B). She was discharged to subacute care.

\section{Discussion}

Radiological evidence of spontaneous air leak was found in seven patients (incidence $0.72 \%$ ) with event onset $9 \pm 9$ days (mean \pm SD) from COVID-19 symptom onset and $6 \pm 8$ days (mean \pm SD) from admission. Our cohort had no gastrointestinal/thoracic/vascular procedures or chest compressions during hospitalization. Five out of seven patients required intubation, but all pneumomediastinum/pneumothorax events occurred before intubation. No difference in age, gender, body mass index, or medical histories as compared to other COVID-19 patients was noted except for three out of seven patients having an obstructive lung disease. One out of seven spontaneous air leak patients expired. Five out of six discharged patients had resolution of their air leak. All 10 patients with an air leak after intubation expired. CT chest of patient number 5 from our series, who expired, is depicted in Figure 1 - 5A pre-intubation, with progression in Figure 1 - 5B postintubation.

\section{Conclusions}

We presume that COVID-19 infection leading to acute lung injury with associated ARDS might be associated with a spontaneous air leak, and further investigations are warranted to delineate mechanisms and impact on outcomes.

\section{Additional Information}




\section{Cureus}

\section{Disclosures}

Human subjects: Consent was obtained by all participants in this study. Ascension Providence Hospital Institutional Review Board issued approval 1587648-1. Conflicts of interest: In compliance with the ICMJE uniform disclosure form, all authors declare the following: Payment/services info: All authors have declared that no financial support was received from any organization for the submitted work. Financial relationships: All authors have declared that they have no financial relationships at present or within the previous three years with any organizations that might have an interest in the submitted work. Other relationships: All authors have declared that there are no other relationships or activities that could appear to have influenced the submitted work.

\section{References}

1. Chu CM: Spontaneous pneumomediastinum in patients with severe acute respiratory syndrome . Eur Respir J. 2004, 23:802-804. 10.1183/09031936.04.00096404

2. Iyer VN, Joshi AY, Ryu JH: Spontaneous pneumomediastinum: analysis of 62 consecutive adult patients . Mayo Clin Proc. 2009, 84:417-421. 10.1016/S0025-6196(11)60560-0

3. Wang J. Su X, Zhang T, Zheng C: Spontaneous pneumomediastinum: a probable unusual complication of coronavirus disease 2019 (COVID-19) pneumonia. Korean J Radiol. 2020, 21:627-628. 10.3348/kjr.2020.0281

4. Sun R, Liu H, Wang X: Mediastinal emphysema, giant bulla, and pneumothorax developed during the course of COVID-19 pneumonia. Korean J Radiol. 2020, 21:541-544. 10.3348/kjr.2020.0180

5. Chan MS, Chan IY, Fung KH, Poon E, Yam LY, Lau KY: High-resolution CT findings in patients with severe acute respiratory syndrome: a pattern-based approach. AJR Am J Roentgenol. 2004, 182:49-56. 10.2214/ajr.182.1.1820049 